\title{
Obesity, Parent Perceptions, Child Feeding, and Food Security in First Generation Hispanic Families
}

\author{
Jill Berg ${ }^{1}$, Susan Tiso ${ }^{1}$, Merry Grasska ${ }^{2}$, Edwin $\operatorname{Tan}^{1}$, Yasmin Chowdhury ${ }^{1}$, Robynn Zender ${ }^{1}$, \\ Mary Knudtson ${ }^{1}$ \\ ${ }^{1}$ University of California, Irvine \\ ${ }^{2}$ Newport Mesa Unified School District
}

\begin{abstract}
Purpose: This study aimed to determine the relationships between parent and child weight status, parental perceptions of weight, child feeding, food insecurity, and acculturation in Hispanic preschoolers and their parents in a southern California school district. Methods: Eighty-five parent-child dyads participated. Height and weight, parental weight perceptions, child feeding, acculturation, and food insecurity data were obtained. Results: Eighty-five percent of parents were born in Mexico, although $94 \%$ of their children were born in the US. Eighty percent of parents and $43 \%$ of the children were overweight or obese. None of the constructs measured predicted child BMI, although parents significantly underestimated their children's body size. Parents' BMI correlated positively with restrictive child feeding practices, and obese parents pressured their children to eat more than did non-obese parents. Conclusions: Obesity exists disproportionately in Hispanics compared to other ethnic populations. While factors predicting children's weight status are difficult to identify, parents' weight, perceptions of child's weight, adherence to the Hispanic culture, and food insecurity do appear to impact parental concerns and parenting behaviors, particularly restrictive and pressuring-to-eat behaviors. Parental underestimation of their children's weight may hinder behavior change if concerns about unhealthy weight are inaccurate. Interventions should consider parental weight, weight perceptions, and feeding practices.
\end{abstract}

(c) 2013 Californian Journal of Health Promotion. All rights reserved.

Keywords: Childhood obesity, Hispanic, BMI, child feeding, acculturation, weight perceptions

\section{Introduction}

Children of Mexican descent continue to have overweight and obesity prevalences greater than non-Hispanic White and Black pre-schoolers, with an estimated $32 \%$ of boys and $23 \%$ of girls overweight or obese (Ogden, Carroll, Curtin, Lamb, \& Flegal, 2010). Parental weight status, country of birth, food insecurity, parental perceptions of child's weight, acculturation, and child feeding practices have been investigated for their contribution to childhood obesity (Clark, Goyder, Bissell, Blank, \& Peters, 2007; Ward, 2008; Warschburger \& Kroller, 2009) . However, few studies encompass all these factors and rarely do they focus on preschoolaged children of first-generation Hispanic parents specifically. Parents' ability to accurately determine overweight and obesity in their children is largely deficient in most populations studied (Doolen, Alpert, \& Miller, 2009), but little is known about what factors contribute to such misclassifications, and whether more accurate assessments are important for achieving and maintaining a healthier childhood weight. Food insecurity and greater adherence to native culture predict adult and child overweight, and restriction of children's eating is associated with greater child weight (Clark et al., 2007).

This brief report presents preliminary findings of the prevalence of overweight/obesity in a population of low-income Hispanic preschool children living in southern California. We also present outcomes related to children's weight, parental perceptions about their children's weight, feeding behaviors, acculturation, and food insecurity. The study aims to improve our 
Berg J., Tiso S., Grasska M., Tan E., Chowdhury Y., Zender R., \& Knudtson M. / Californian Journal of Health Promotion 2013,

Volume 11, Issue 3, Pages 86-92

understanding of the relationships between these factors and obesity in a first-generation, lowincome Hispanic population in order to inform programs that address obesity in this population.

\section{Methods}

\section{Participants}

Approval for this project was granted by the IRB and the cooperating school district. Participants in this cross-sectional study were recruited during three separate health fairs in a southern Californian Orange County school district, serving a low-income Spanish speaking population. About $40 \%$ of kindergarten students enrolled in the target school district are English learners, 93\% of whom speak Spanish (http://dq.cde.ca.gov/dataquesthttp://dq.cde.ca.g ov/dataquest/). Eligibility for the reduced or free lunch program in these schools is between $74 \%$ and $\quad 95 \%$ (http://publicschoolsk12.com). Participants were Hispanic parents and children enrolled in the preschool program in the school district. Hispanic parents who visited our health fair booth were offered participation in the study after study was described and study activities explained. If interested, they signed a consent form.

\section{Procedures and Measures}

Participants then entered a semi-private area behind the fair booth where anthropometric evaluations of height and weight were taken by a nurse practitioner or supervised nurse practitioner student. Participants sat while completing pencil and paper surveys in either English or Spanish, per participant request. Completion of the full packet of surveys took approximately 20 minutes. Height and weight measurements of children and parents were taken to calculate body mass index (BMI). Parental weight perceptions (using the Body Image Measure [Killion, Hughes, Wendt, Pease, \& Nicklas, 2006]), child feeding practices (The Child Feeding Questionnaire [CFQ] [Birch, Fisher, Grimm-Thomas, Markey, Sawyer, \& Johnson, 2001).]), acculturation status (Bidimensional Acculturation Scale [BAS] [Marín \& Gamba, 1996]), and food insecurity (The Household Food Insecurity Access Scale
[HFIAS] [Coates, Swindale, \& Bilinsky, 2007]) were obtained.

\section{Analyses}

Data were analyzed using IBM SPSS statistics 19 (Armonk, New York). Dependent sample ttests compared differences between 1) parent's perception of a healthy child's BMI and parent's perception of their child's BMI and, 2) parent's perception of their child's BMI and the child's actual BMI. Obese/overweight parents' feeding practices were then compared to healthy parents' feeding practices using independent sample ttests. Linear regression and correlation coefficients were calculated to determine associations between variables including BMI, child feeding, acculturation, and food insecurity. Multiple linear regression analysis was then conducted to control for possible confounding variables.

\section{Results}

\section{Descriptive Statistics}

Results of demographics and weight status are presented in Tables 1 and 2. Eighty-five parentchild dyads participated in this study. Eightyfive percent of parents were born in Mexico, although $94 \%$ of their children were born in the US. Parents' age averaged 30.91 years $(S D=6.31$ years). Children were between two and five years of age, averaging 3.24 years $(S D=.99$ years). Approximately $48 \%$ of parents had a high school diploma, and nearly $37 \%$ of parents in this sample had less than a high school education. A majority of parents reported not having health insurance (69.9\%).

Eighty percent of parents and $43 \%$ of their children were overweight or obese. On average, parents had a BMI of 29.06 (SD = 4.81), with $40 \%$ being overweight, and $40 \%$ obese. The children in our sample had an average BMI of $17.30(\mathrm{SD}=2.58)$, falling at the $70.8^{\text {th }}$ percentile, with nearly equal numbers of children having BMI percentiles in the healthy range $(41.7 \%)$ and in the overweight or obese range $(42.8 \%)$, the latter category split evenly between the overweight and obese categories at $21.4 \%$ each. 
Berg J., Tiso S., Grasska M., Tan E., Chowdhury Y., Zender R., \& Knudtson M. / Californian Journal of Health Promotion 2013,

Table 1

\begin{tabular}{lr}
$\begin{array}{c}\text { Demographic Characteristics of } \\
\text { (n= 85) }\end{array}$ \\
\hline Mean Age (SD) & $30.91(6.31)$ \\
Birthplace & \\
$\quad$ US & $7.1 \%$ \\
Mexico & $84.7 \%$ \\
Other country & $8.3 \%$ \\
Parental education & \\
$\quad$ Less than high school & $16.7 \%$ \\
$\quad$ Some high school & $20.2 \%$ \\
High school diploma & $47.6 \%$ \\
$\quad$ Some college & $14.3 \%$ \\
$\quad$ College & $1.2 \%$ \\
Food Insecurity & \\
$\quad$ Food Secure: & $80.5 \%$ \\
$\quad$ Mild Insecurity: & $11.7 \%$ \\
$\quad$ Moderate Insecurity: & $2.6 \%$ \\
$\quad$ Severe Insecurity: & $5.2 \%$ \\
Health Insurance & \\
$\quad$ Yes & \\
$\quad$ No & $30.1 \%$ \\
\hline
\end{tabular}

Table 2

Body Mass Index of Parents and Children

\begin{tabular}{llr}
\hline Weight status- Parent & $(\mathrm{BMI})$ & \\
\hline Underweight & $(\leq 18.5)$ & $2.4 \%$ \\
Healthy & $(18.5-24.9)$ & $17.6 \%$ \\
Overweight & $(25-29.9)$ & $40.0 \%$ \\
Obese & $(\geq 30.0)$ & $40.0 \%$ \\
\hline Weight status- Child & $(\mathrm{BMI}$ percentile* & \\
\hline Underweight & $\left(<25^{\text {th }}\right.$ percentile $)$ & $15.4 \%$ \\
Healthy & $\left(25^{\text {th }}-85^{\text {th }}\right.$ percentile $)$ & $41.7 \%$ \\
Overweight & $\left(85^{\text {th }}-95^{\text {th }}\right.$ percentile $)$ & $21.4 \%$ \\
Obese & $\left(>95^{\text {th }}\right.$ percentile $)$ & $21.4 \%$ \\
\hline
\end{tabular}

*Weight classification of BMI for children

differs than that for adults, as child

classifications are based on weight-for-age growth charts.

Over $80 \%$ of households to be food secure: about $12 \%$ were mildly insecure, $3 \%$ moderately insecure, and $5 \%$ were severely insecure. The responses to the acculturation scale in our sample indicated that $96 \%$ of participants retained a high level of adherence to the Hispanic domain, 29\% adhered highly to the
English domain, and 26\% demonstrated bicultural adherence, conforming highly to both domains.

\section{Inferential Statistics}

Actual and Perceived BMI. Parents' actual BMI was not associated with children's BMI percentile, and parents had difficulty accurately perceiving their child's weight, even though their perceptions of their own weight, and of what constitutes a healthy weight of a hypothetical child, were accurate. Parent BMI was not significantly associated with children's BMI percentile. Parents significantly underestimated their child's BMI when compared to the child's actual BMI $(p<.001)$. Additionally, children's actual BMI was much higher than the BMI parents indicated for a healthy boy $(p<.001)$ and a healthy girl $(p<.001)$. Forty-one percent $(41 \%)$ of parents misclassified their overweight or obese child as healthy (ns), and 1.2\% misclassified their healthy weight child as obese or overweight. Parent's BMI (as a continuous variable), however, correlated positively with their perceptions of their own weight $(p<.001)$, meaning that parents accurately perceived their weight regardless of their actual BMI. Therefore, although parents accurately perceived their own weight, they did not accurately perceive the weight of their child. Parents' BMI also correlated positively with restrictive feeding practices of their children $(p<.05)$.

Child Feeding. Parents' perception of their children's body size, having responsibility for feeding, and degree of food insecurity was associated with concern over body weight, and monitoring, restricting, and pressuring feeding behaviors. Parents' perception of their children's body size was positively related to their concern about their child's weight $(p<.05)$, and both responsibility for feeding and concern about child's weight were related to monitoring behaviors by parents $(p<.01$ and $p<.05$, respectively). Parents who restricted child's feeding also pressured their kids to eat $(p<.05)$. Restricted feeding behaviors were positively associated with food insecurity $(p<.05)$.

Obese Versus Healthy Weight Parents. Few differences were found between obese and healthy weight parents, with the exception of the 
Berg J., Tiso S., Grasska M., Tan E., Chowdhury Y., Zender R., \& Knudtson M. / Californian Journal of Health Promotion 2013,

Volume 11, Issue 3, Pages 86-92

amount of pressure they exerted on their children to eat $(p=.03)$. Specifically, obese parents pressured their children to eat more than did overweight parents $(p<.001)$ and parents of a healthy weight $(p<.01)$. Obese parents did not differ from parents of a healthy weight with respect to being responsible for feeding their child ( $p=.23)$, concern for their child's weight $(p=.77)$, restricting their child's food $(p=.12)$, nor monitoring of their child's eating habits $(p=.94)$.

Regression analysis revealed no variables or combination of variables that predicted child BMI. Furthermore, no combination of variables added to the existing significant correlations accounted for a greater amount of variation in the data.

\section{Discussion}

The prevalence of obesity in our study is consistent with CDC statistics of obesity among adult Mexican-Americans at 39.3\% (Flegal, Carroll, Ogden, \& Curtin, 2010). The prevalence of obesity among children in our study (21.4\%) was twice the prevalence of all 2 - 5 year olds in the US population (10.4\%), and more than other low-income preschoolers in the U.S. (14.5\%), but mirrors that of other studies reporting obesity prevalence of about 22\% among Hispanic preschool-aged kids (Sharma et al., 2009). Parents in our sample significantly underestimated their child's body weight, which is consistent with numerous studies and cuts across racial, socioeconomic, and geo-cultural lines (Doolen et al., 2009; De La O et al., 2009). A review by Parry, Netuveli, Parry, and Saxena (2008) discovered fewer than 50\% of parents across 19 different studies accurately recognized their child's weight status. Children also underestimate their own weight (Chaimovitz, Issenman, Moffat, \& Persad, 2008), as have teachers (Jimenez-Cruz, Bacardi-Gascon, Castellon-Zaragoza, Garcia-Gallardo, \& Hovell, 2007), and even physicians (Chaimovitz et al., 2008). Furthermore, children's actual BMI in our study was much higher than the BMI parents thought was a healthy weight. Given the significant misclassification of their child's weight, in addition to believing a healthy child's weight is less than the actuality of the weight of their child, a disconnect may exist between knowing what a healthy weight is and being able to apply this standard to one's own child. This same dynamic was noted by Warschburger and Kroller (2009).

While both children and parents in our sample had obesity rates on par with other national statistics, parental obesity did not predict child obesity, as it has in other studies (Freedman, Khan, Serdula, Dietz, Srinivasan, \& Berenson, 2005). The reason for the lack of association between parent and child BMI in our study is unknown. It may simply be sampling or sample size factors, mediation by a construct we did not measure, or that there truly is no association in this population. We found only one other study reporting no association between parent and child BMI, but that study found the relationship was mediated by restrictive parental feeding behaviors and disinhibited child eating behaviors (Joyce \& Zimmer-Gembeck, 2009). Furthermore, associations between parent and child weight, feeding habits, and acculturation may have been attenuated in our sample given that parents were primarily first-generation Mexican-Americans: a factor shown to be protective against developing obesity in this population (Semmler, Ashcroft, Van Jaarsveld, Carnell, \& Wardle, 2009; Liu, Chu, Frongillo, \& Probst, 2012). The lack of association may also relate to the age of the children in our study such that as these preschool children age their weight will more strongly correlate with the weight of their parents (Batis, Popkin, Hernandez-Barrera, Barquera, \& Rivera, 2011).

While none of the constructs measured in our study predicted child BMI, parents' BMI correlated significantly with restrictive child feeding practices, and obese parents pressured their children to eat more than did non-obese parents. Factors predicting children's weight status are difficult to identify, although parents' weight, perceptions, acculturation, and food insecurity do appear to impact parental concerns and parenting behaviors, particularly restrictive and pressuring-to-eat behaviors. Parental underestimation of their children's weight may hinder behavior change if concerns about overweight and obesity are blunted by 
Berg J., Tiso S., Grasska M., Tan E., Chowdhury Y., Zender R., \& Knudtson M. / Californian Journal of Health Promotion 2013,

Volume 11, Issue 3, Pages 86-92

inaccurate perceptions. Interventions should consider parental weight status, weight perception accuracy, acculturation, food insecurity, and feeding practices.

\section{Limitations}

The main factor limiting the results and impact of this study is its small sample size. It is possible that, given a greater number of participants, more relationships between measured outcomes would be apparent, especially regarding parent and child BMI correlations. There are also other indicators of obesity, such as hip to waist ratio measurements (Erinosho, Berrigan, Thompson, Moser, Nebeling, \& Yaroch, 2012), and waist to height ratios (Petursson, Sigurdsson, Bengtsson, Nilsen, \& Getz, 2011), that might have been more strongly related to outcomes of interest in this study. Using these measures, rather than merely weight and height, can more accurately reflect fat distribution within the body, suggesting health risks associated with adipose deposition patterns (i.e. abdominal versus lower body deposition) (Khoury M et al., 2012).

\section{Implications}

Implications from this study suggest that parental weight status impacts parental perceptions of child weight and parental feeding behaviors. Additionally, parents often inaccurately assess the weight of their child. Participants in our study were first-generation low-income Hispanic parents, the majority of whom carried excess weight. Parental acculturation, weight, and feeding behaviors may be less of a factor in childhood feeding and obesity among first-generation MexicanAmericans, especially for 3 - 5 year olds. However, because rather drastic increases in weight and food quantities occur as future generations live in the U.S., interventions should address negative impacts of pressuring kids to eat, and of food restriction. Including children in educational and/or cooking, nutrition, or foodrelated programs may also prove effective. Interventions aimed at bringing parental perceptions of child weight into agreement with actual weight measures may prove to be a critical base for attaining meaningful change in childhood

\section{References}

Batis, C., Popkin, B.M., Hernandez-Barrera, L., Barquera, S., \& Rivera, J.A. (2011). Food acculturation drives dietary differences among Mexicans, Mexican Americans, and non-hispanic whites. Journal of Nutrition, 141(10), 1898-1906.

Birch, L. L., Fisher, J. O., Grimm-Thomas, K., Markey, C. N., Sawyer, R., \& Johnson, S. L. (2001). Confirmatory factor analysis of the Child Feeding Questionnaire: a measure of parental attitudes, beliefs and practices about child feeding and obesity proneness. Appetite, 36(3), 201-210.

Chaimovitz, R., Issenman, R., Moffat, T., \& Persad, R. (2008). Body perception: Do parents, their children, and their children's physicians perceive body image differently? Journal of Pediatric Gastroenterology and Nutrition, 47(1), 76-80.

Clark, H. R., Goyder, E., Bissell, P., Blank, L., \& Peters, J. (2007). How do parents’ ～child-feeding behaviours influence child weight? Implications for childhood obesity policy. Journal of Public Health, 29(2), 132-141.

Coates, J., Swindale, A., \& Bilinsky, P. (2007). Household Food Insecurity Access Scale (HFIAS) for measurement of food access: indicator guide. Washington, DC: Food and Nutrition Technical Assistance Project, Academy for Educational Development.

De La O, A., Jordan, K. C., Ortiz, K., Moyer-Mileur, L. J., Stoddard, G., Friedrichs, M., ... Mihalopoulos, N. L. (2009). Do Parents Accurately Perceive Their Child’s Weight Status? Journal of Pediatric Health Care, 23(4), 216-221.

Doolen, J., Alpert, P. T., \& Miller, S. K. (2009). Parental disconnect between perceived and actual weight status of children: A metasynthesis of the current research. Journal of the American Academy of Nurse Practitioners, 21(3), 160-166. 
Berg J., Tiso S., Grasska M., Tan E., Chowdhury Y., Zender R., \& Knudtson M. / Californian Journal of Health Promotion 2013,

Volume 11, Issue 3, Pages 86-92

Erinosho, T., Berrigan, D., Thompson, F., Moser, R., Nebeling, L., \& Yaroch, A. (2012). Dietary Intakes of Preschool-Aged Children in Relation to Caregivers' Race/Ethnicity, Acculturation, and Demographic Characteristics: Results from the 2007 California Health Interview Survey. Maternal and Child Health Journal, 16(9), 1844-1853.

Flegal, K. M., Carroll, M. D., Ogden, C. L., \& Curtin, L. R. (2010). Prevalence and Trends in Obesity Among US Adults, 1999-2008. The Journal of the American Medical Association, 303(3), 235241.

Freedman, D. S., Khan, L. K., Serdula, M. K., Dietz, W. H., Srinivasan, S. R., \& Berenson, G. S. (2005). The relation of childhood BMI to adult adiposity: the Bogalusa Heart Study. Pediatrics, 115(1), 22-27.

Jimenez-Cruz, A., Bacardi-Gascon, M., Castellon-Zaragoza, A., Garcia-Gallardo, J., \& Hovell, M. (2007). Perception of body size among Mexican teachers and parents. Nutricion Hospitalaria, 22(5), 560.

Joyce, J. L., \& Zimmer-Gembeck, M. J. (2009). Parent feeding restriction and child weight. The mediating role of child disinhibited eating and the moderating role of the parenting context. Appetite, 52(3), 726-734.

Khoury, M., Manlhiot, C., Dobbin, S., Gibson D., Chahal, N., Wong, H., ... McCrindle BW. (2012). Role of waist measures in characterizing the lipid and blood pressure assessment of adolescents classified by body mass index. Archives of pediatrics \& adolescent medicine, 166(8), 719-24.

Killion, L., Hughes, S. O., Wendt, J. C., Pease, D., \& Nicklas, T. A. (2006). Minority mothers' perceptions of children's body size. International Journal of Pediatric Obesity, 1(2), 96-102.

Liu, J.-H., Chu, Y.H., Frongillo, E.A., \& Probst, J.C. (2012). Generation and acculturation status are associated with dietary intake and body weight in Mexican American adolescents. Journal of Nutrition, 142(2), 298-305.

Marín, G., \& Gamba, R. J. (1996). A New Measurement of Acculturation for Hispanics: The Bidimensional Acculturation Scale for Hispanics (BAS). Hispanic Journal of Behavioral Sciences, 18(3), 297-316.

Ogden, C. L., Carroll, M. D., Curtin, L. R., Lamb, M. M., \& Flegal, K. M. (2010). Prevalence of High Body Mass Index in US Children and Adolescents, 2007-2008. JAMA: The Journal of the American Medical Association, 303(3), 242-249.

Parry, L. L., Netuveli, G., Parry, J., \& Saxena, S. (2008). A Systematic Review of Parental Perception of Overweight Status in Children. The Journal of ambulatory care management, 31(3), 253-268.

Petursson, H., Sigurdsson, J. A., Bengtsson, C., Nilsen, T. I., \& Getz, L. (2011). Body configuration as a predictor of mortality: comparison of five anthropometric measures in a 12 year follow-up of the Norwegian HUNT 2 study. PloS one, 6(10).

Semmler, C., Ashcroft, J., Van Jaarsveld, C. H. M., Carnell, S., \& Wardle J. (2009). Development of overweight in children in relation to parental weight and socioeconomic status. Obesity, 17(4), 814-820.

Sharma, A. J., Grummer-Strawn, L. M., Dalenius, K., Galuska, D., Anandappa, M., Borland, E., ... Smith, R. (2009). Obesity prevalence among low-income, preschool-aged children-United States, 1998-2008. Morbidity and Mortality Weekly Report, 58(28), 769-773.

Ward, C. L. (2008). Parental perceptions of childhood overweight in the Mexican-American population: an integrative review. Journal of School Nursing, 24(6), 407-416.

Warschburger, P., \& Kröller, K. (2009). Maternal perception of weight status and health risks associated with obesity in children. Pediatrics, 124(1), e60-e68. 


\author{
Author Information \\ *Jill Berg, PhD, RN \\ Associate Professor \\ Chair, Graduate Programs \\ Program in Nursing Science \\ 252 Berk Hall \\ University of California, Irvine \\ Irvine, CA 92697-3959 \\ 949.824.0696 \\ jpberg@uci.edu \\ Susan Tiso, DNP, MN, FNP \\ Program in Nursing Science \\ 252 Berk Hall \\ University of California, Irvine \\ Irvine, CA 92697-3959 \\ Merry Grasska, MPH, RN, FNPC \\ Director, Hope Clinic \\ Newport-Mesa Unified School District \\ 2045 Meyer Place, \#A \\ Costa Mesa, CA 92627 \\ Edwin Tan, PhD \\ Program in Nursing Science \\ 252 Berk Hall \\ University of California, Irvine \\ Irvine, CA 92697-3959 \\ Yasmin Chowdhury, MPH \\ 252 Berk Hall \\ University of California, Irvine \\ Irvine, CA 92697-3959 \\ Robynn Zender, MS \\ 252 Berk Hall \\ University of California, Irvine \\ Irvine, CA 92697-3959 \\ Mary Knudtson, DNSc, NP \\ Program in Nursing Science \\ 252 Berk Hall \\ University of California, Irvine \\ Irvine, CA 92697-3959 \\ * corresponding author
}

